\title{
Combining sap flow measurements and modelling to assess water needs in an oasis farmland shelterbelt of Populus simonii Carr in Northwest China
}

\author{
Shuai Fu ${ }^{\mathrm{a}, \mathrm{c}, \mathrm{d}}$, Lin Sun ${ }^{\mathrm{b}}$, Yi Luo ${ }^{\mathrm{a}, \mathrm{b}, \mathrm{d}, *}$ \\ a State Key Laboratory of Desert and Oasis Ecology, Xinjiang Institute of Ecology and Geography, Chinese Academy of Sciences, Urumqi 830011, PR China \\ ${ }^{\mathrm{b}}$ Institute of Geographic Science and Natural Resources Research, Chinese Academy of Sciences, Beijing 100101, PR China \\ ' School of Resources, Environmental \&' Chemical Engineering, Nanchang University, Nanchang 330031, PR China \\ d University of Chinese Academy of Sciences, Beijing 100049, PR China
}

\section{A R T I C L E I N F O}

\section{Article history}

Received 17 December 2015

Received in revised form 6 June 2016

Accepted 10 July 2016

Available online 29 July 2016

\section{Keywords:}

Water needs

Conductance

Farmland shelterbelt

Water stress

\begin{abstract}
A B S T R A C T
Farmland shelterbelts provide an ecological protection screen for an oasis but exhibit high mortality in the face of water shortage. It is necessary to understand farmland shelterbelt tree transpiration under different levels of water stress and stand ages for proper management. Sap flux measurement techniques and models are among the most useful method to detect water stress and to evaluate plant water consumption. The usefulness of both methods decreases, however, when applied to species, such as Populus simonii Carr, that have an outstanding tolerance to drought and a remarkable capacity to take up water from drying soils. Our hypothesis is that analysis using simultaneous measurements of sap flow and models in the same trees is useful for assessing the irrigation needs in farmland shelterbelts. To test our hypothesis, we analysed the relationships between canopy transpiration, canopy conductance, relative extractable water and atmospheric factors in a farmland shelterbelt and evaluated the effectiveness of the model. Measurements were made during one growing season. The time courses of sap flow measured and modelled on days of contrasting weather and soil water conditions were analysed to evaluate the usefulness of the method to assess the crop water needs. We calculated the daily tree water consumption from sap flow measurements and the parameterized modified Jarvis-Stewart model, and we evaluated the model's usefulness to assess the final water needs under water stress and stand ages for farmland shelterbelt irrigation. The transpiration decreased as the soil drought increased, and it increased as the atmospheric drought increased. The time course of the water needs showed that the occurrence of water stress in the farmland shelterbelt trees had a large impact on their water consumption, which increased as the water stress decreased, following the equation $y=1 /\left[1+\mathrm{e}^{-60.67 \times(\operatorname{REWx}-0.402)}\right]$. The simultaneous use of modelling and tree structural data increased the reliability of assessing water needs from youth to maturity. A similar analysis with the water consumption values, from which stand age values were derived, showed that water needs increased with the tree age following the equation $y=847-844 /\left[1+(x / 87.9)^{1.9}\right]$. We conclude that compared to the use of sap flow records alone, the simultaneous use of sap flow records and model values provides more detailed information to assess water needs in a farmland shelterbelt, which has an important significance for farmland shelterbelt protection.
\end{abstract}

(c) 2016 Elsevier B.V. All rights reserved.

\footnotetext{
* Corresponding author at: State Key Laboratory of Desert and Oasis Ecology, Xinjiang Institute of Ecology and Geography, Chinese Academy of Sciences, Urumqi 830011, PR China.

E-mail addresses: fu_shuai@yahoo.com (S. Fu), Sunlin-Cas@hotmail.com (L. Sun), luoyi.cas@hotmail.com (Y. Luo).
}

\section{Introduction}

Water is becoming an increasingly scarce resource, and its shortage has become a growing threat to the growth of artificial forests in semi-arid land (Chen et al., 2008). As an important form of artificial forest, farmland shelterbelts provide an ecological protection screen for agriculture (Fan et al., 2002; Ryszkowski and Kedziora, 2007), and these shelterbelts decline with water shortage. Water-saving agricultural technology is widely used in semi-arid 
regions (Shan et al., 2002). Low-pressure pipeline technology, micro-irrigation techniques and sprinkler-irrigation techniques are often carried out in semi-arid agriculture (Xinli, 2006), and these techniques either prevent water side supplying or deep percolation (Kang et al., 2012; Xinli, 2003), causing the farmland shelterbelt to decline. Infant farmland shelterbelt trees and even mature trees exhibit high mortality from water shortages. Moreover, only a few woodland or agro-forestry areas were established after two decades (Xiubin et al., 2003). In recent decades, a large amount of cultivated land had to be discarded because of the lack of farmland shelterbelt protection (Chen et al., 2007). To encourage the protection of the agro-forestry system, water use strategies for farmland shelterbelt trees must be investigated. It has become increasingly necessary to understand farmland shelter tree transpiration under water stress and growth periods (Anderegg et al., 2012, 2013).

Sap flow techniques are routinely used to estimate the transpiration from canopies of woody plants, typically without any local calibration. However, it cannot explain the response of soil water and meteorological factors. Coupled with a model, this issue could be resolved. Canopy transpiration $\left(E_{c}\right)$ is the main factor in the evaluation of tree transpiration (Cermak et al., 2004; Chang et al., 2006; Zeppel et al., 2008). $\mathrm{E}_{\mathrm{c}}$ depends on a number of sitespecific parameters that relate to the physical properties of the soil, the vegetation and the ambient meteorological conditions (Bonan, 2008; Chen et al., 2012; Jung et al., 2014; Li et al., 2013, 2010; She et al., 2013; Whitley et al., 2013). Solar radiation, VPD, and soil moisture are the primary determinants of transpiration (Jung et al., 2014; She et al., 2013). Numerous modelling methods are available to estimate transpiration from these driving parameters. Some methods used semi-empirical relationships between the water and soil fluxes and vegetation and atmospheric conditions, such as the Penman-Monteith (PM) equation (Monteith, 1965), whereas others used empirical relationships between canopy water fluxes and meteorological drivers, such as Jarvis-type models (Jarvis and McNaughton, 1986; Lagergren and Lindroth, 2002; Whitley et al., 2013). Because of the semi-mechanistic basis of the PM equation, there is a wide appeal in using it to estimate rates of tree water use. However, its implementation is often limited by the need for aerodynamic and canopy conductance $\left(g_{c}\right)$ data. Aerodynamic conductance often exerts a negligible effect on transpiration and could be calculated from wind speed (She et al., 2013; Sommer et al., 2002; Whitley et al., 2009). However, the response of $g_{c}$ to the influencing factors has been incorporated into land surface models for transpiration estimation (Wang et al., 2014). gc is a key parameter in controlling energy and water exchanges between the canopy and atmosphere (Han et al., 2011) and depends mainly on soil moisture, air temperature and relative humidity (Gharun et al., 2013). Canopy conductance models have been widely constructed following the Jarvis-Stewart approach (Jarvis, 1976; Stewart, 1988), which calculates the canopy conductance from the maximum stomatal conductance by applying different stress functions related to the influencing factors (Jonard et al., 2011; Naithani et al., 2012; She et al., 2013). Transpiration can be estimated by coupling with meteorological factors and the canopy conductance (She et al., 2013; Yunusa et al., 2000).

The purpose of this research was to evaluate the usefullness of simultaneous sap flow measurements and modelling for detecting the water consumption during water stress in farmland shelterbelts

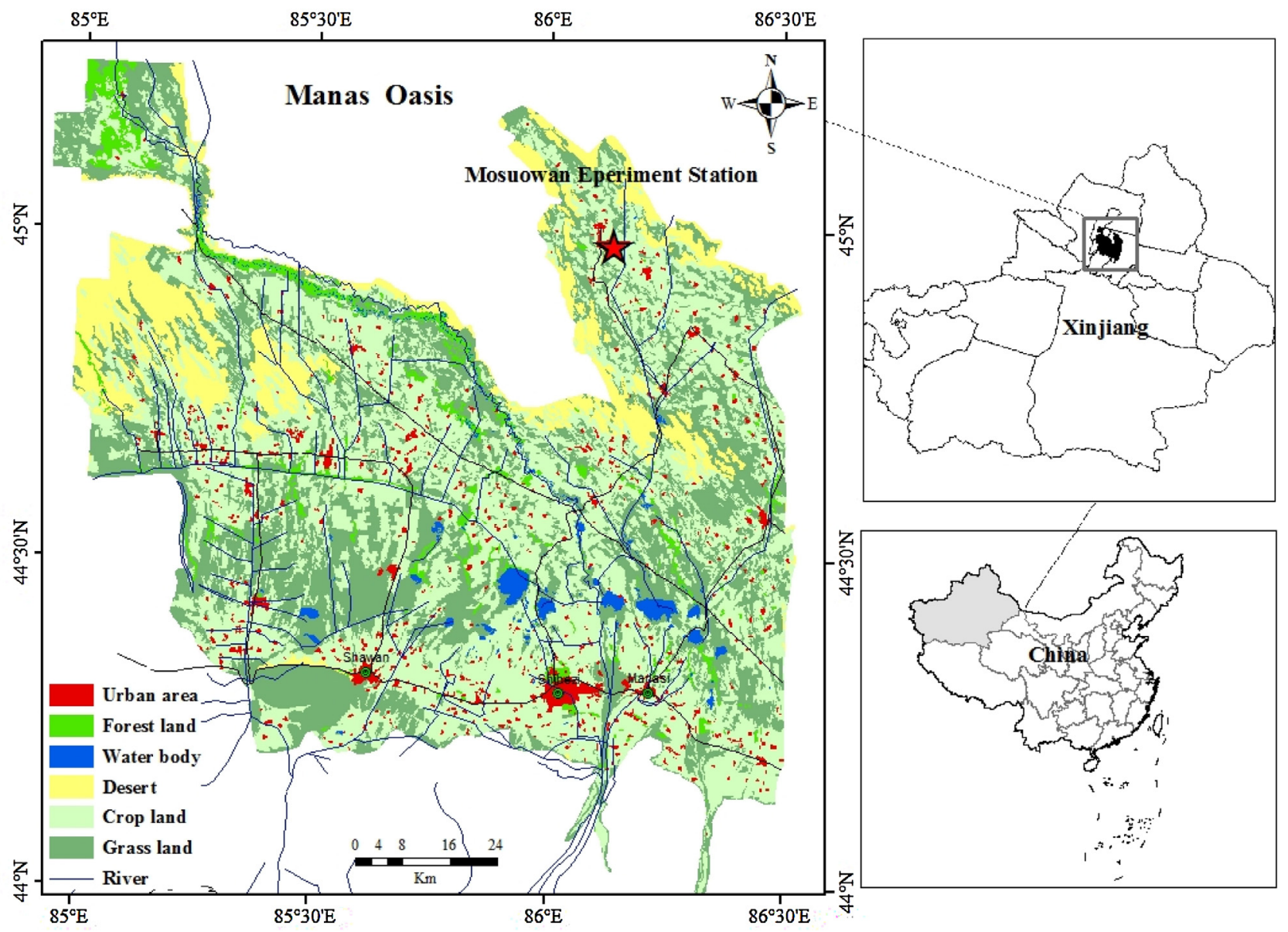

Fig. 1. The location of the Manas Oasis. 
Table 1

Basic physical and chemical property of soil.

\begin{tabular}{|c|c|c|c|c|c|c|}
\hline Depth $(\mathrm{cm})$ & Soil textures & $\begin{array}{l}\text { Bulk density } \\
\left(\mathrm{g} \mathrm{cm}^{-3}\right)\end{array}$ & $\begin{array}{l}\text { Saturated } \\
\text { water content } \\
\left(\mathrm{cm}^{3} \mathrm{~cm}^{-3}\right)\end{array}$ & $\begin{array}{l}\text { Field capacity } \\
\left(\mathrm{cm}^{3} \mathrm{~cm}^{-3}\right)\end{array}$ & $\mathrm{PH}$ & $\begin{array}{l}\text { Soil salt } \\
\left(\mathrm{g} \mathrm{kg}^{-1}\right)\end{array}$ \\
\hline 0-20 & Medium Loam & 1.48 & 0.42 & 0.30 & 8.15 & 0.72 \\
\hline $20-40$ & Medium Loam & 1.51 & 0.46 & 0.33 & 8.17 & 0.74 \\
\hline $40-60$ & Medium Loam & 1.57 & 0.47 & 0.33 & 8.23 & 0.65 \\
\hline $60-80$ & Medium Loam & 1.53 & 0.43 & 0.31 & 8.41 & 0.85 \\
\hline $80-100$ & Medium Loam & 1.59 & 0.38 & 0.28 & 8.37 & 1.03 \\
\hline $100-120$ & Sandy Loam & 1.67 & 0.32 & 0.25 & 8.29 & 0.96 \\
\hline $120-150$ & Sandy Loam & 1.77 & 0.32 & 0.25 & 8.46 & 1.10 \\
\hline
\end{tabular}

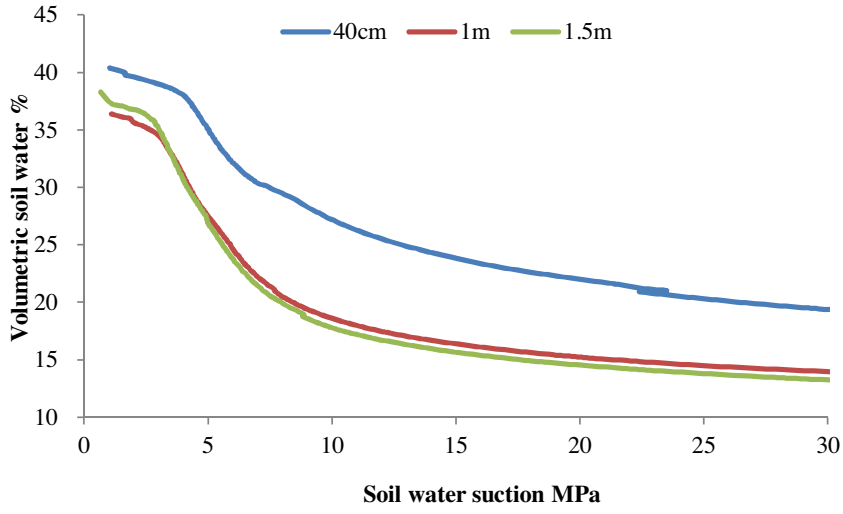

Fig. 2. Soil moisture characteristics curve of different depth.

and the effect of the tree water stress on its water consumption. A second goal is to assess water needs under different levels of water stress and at different stand ages. We analysed the relationships among the canopy conductance and transpiration with the soil water content and climatic factors in a farmland shelterbelt comprising Populus simonii Carr trees with different stand ages.

\section{Materials and methods}

\subsection{Study site}

The study was conducted in Manas Oasis, located southwest of the Zhungaer Basin in Xinjiang, with geographical coordinatesof $\mathrm{E} 85^{\circ} 0 \mathrm{l}^{\prime}-86^{\circ} 32^{\prime}, \mathrm{N}^{\prime} 3^{\circ} 27^{\prime}-45^{\circ} 2 \mathrm{l}^{\prime}$ (Fig. 1). Manas Oasis is in the north of Xinjiang, and it is known as the "Western Gate" of Urumqi. It is located between the middle range of the northern Tianshan Mountains and the southern border of the Zhungaer Basin. South of it are the famous TianShan mountains, and west of Manas Oasis is the edge of the Zhungaer Basin. Mountains and plains equally share the area. Manas basin covers $5156 \mathrm{~km}^{2}$, with an average altitude is $302.2 \mathrm{~m}$, and a glacier covers $608.25 \mathrm{~km}^{2}$. The main sources of runoff are rain and melt water, of which $34.5 \%$ is melt water. The climate is a temperate continental dry and semi-dry climate, with an annual radiation of $1280 \mathrm{Mcal} \mathrm{m}^{-2}$ (Dong et al., 2011). The annual precipitation is $190.3 \mathrm{~mm}$, concentrated in the April-October period, and the annual evaporation is $1713.4 \mathrm{~mm}$. The soil texture of the plot is generally medium loam (Table 1 ); and under the depth of $1 \mathrm{~m}$, there was sand loam. Because of the different textural soil types between depths, their abilities of suction were various. Table 1 and Fig. 2 showed that the upper soil $(1.0 \mathrm{~m})$ had higher field capacity and stronger water absorption capacity. On average, there are 172 frost-free days, and the annual average air temperature is $6.9^{\circ} \mathrm{C}$. The aspect of this region slopes downwards from the south toward the north and tilts from the southeast to the northwest. The geomorphological sectors include mountains, flat plains, and deserts. The $1.176 \times 10^{9} \mathrm{~m}^{2}$ central alluvial plain is the major agricultural crop growing area. Farmland shelterbelts were installed to protect the agro-forestry system in the oasis in the 1960s (Zhao et al., 2009). The surface soil is grey desert soil and is sandy loam from the depth of $90 \mathrm{~cm}$ (Table 1).

\subsection{Sap flow and meteorological factor measurements}

During the 2014 growing season, sap-flow gauges were installed at breast height in the stems (Granier, 1987) of Populus simonii Carr at the Mosowan experiment stations (Xinjiang Institute of Ecology and Geography, Chinese Academy of Science). The installation and maintenance routine followed the protocol prescribed by the manufacturer. The sap flow (SFD, $\mathrm{cm} \mathrm{m}^{-2} \mathrm{~s}^{-1}$ ) of individual trees was measured with Granier-type heat pulse sensors (TDP80 Dynamax, USA) every $30 \mathrm{~s}$, and 20-min averages were recorded with a data logger (DTKDT80-AL with a multiplexer AM 5/15, Thermo, USA) (Granier, 1987).

Soil water sensors (SM300) were installed at a 10-150 cm depth, and the counts were logged every $20 \mathrm{~min}$ from 20 April 2014 to 10 October 2014 . Soil samples were collected by a soil auger $(5 \mathrm{~cm}$ in diameter) and a ring-knife in the experimental plots at 10 -cm intervals down the soil profile until $200 \mathrm{~cm}$. The soil moisture data used in the subsequent section are based on this calibration. A growth cone was used to measure the sapwood radius and heartwood radius by tape. The diameter at breast height (DBH)was measured by a vernier calliper, the crown radius by tape, and the tree height by a hypsometer. These investigations were conducted on young Populus simonii Carr prior to maturity. Meteorological data were collected from Mosuowan meteorological stations with proximity to the experimental plot.

\subsection{Canopy transpiration and canopy conductance}

A standard calibration is widely used for the heat pulse method (Granier, 1987), relating the sap flow density (SFD, $\mathrm{cm} \mathrm{s}^{-1}$ ) to the difference in temperature between a pair of probes $\left(\Delta T^{\circ} \mathrm{C}\right)$

$S F D=0.0119 K^{1.23}$

where $\mathrm{K}$ (dimensionless) is a parameter calculated as

$K=\frac{\Delta T_{\max }-\Delta T}{\Delta T}$

where $\Delta T_{\max }$ is the value of $\Delta T$ when there is no sap flux, which corresponds to the nocturnal $\Delta T$ maximum over a $24 \mathrm{~h}$ period.

$\mathrm{E}_{\mathrm{c}}=\mathrm{SFD} \times \frac{\mathrm{A}_{\mathrm{sw}}}{\mathrm{A}_{\text {canopy }}}$

where $E_{c}\left(\mathrm{~cm} \mathrm{~s}^{-1}\right)$ is the canopy transpiration rate, $A_{s w}\left(m^{2}\right)$ is the sapwood area, and $A_{\text {canopy }}\left(\mathrm{m}^{2}\right)$ is the canopy area. According to the description (Kumagai et al., 2005), the transpiration is calculated by summing the products of SFD and $A_{s}$. The rates $\left(E, \mathrm{~cm} \mathrm{~h}^{-1}\right.$ ground area) are then normalized by the ground area and converted to units of $\mathrm{cm} \mathrm{d}^{-1}$ to compare with the rainfall (Chen et al., 2012). Canopy 
transpiration is calculated from the transpiration divided by $\mathrm{A}_{\text {canopy }}$ (Eq. (3)).

The qualitative response of the canopy conductance $\left(\mathrm{g}_{\mathrm{c}}, \mathrm{m} \mathrm{s}^{-1}\right)$ to the climate driving force is estimated from the time-averaged transpiration $\left(\mathrm{T}_{\mathrm{r}}, \mathrm{mm}\right)$ per unit canopy area and mean vapour pressure deficit (VPD, k Pa) for the Populus simonii Carr trees. The actual $\mathrm{g}_{\mathrm{c}}$ was calculated from the simple inverted Penman-Monteith equation as (Granier and Loustau, 1994; Han et al., 2012)

$g_{C}=\frac{1}{\Delta R_{n} r_{a} /(\lambda E \gamma)+\rho C_{p} V P D /(\lambda E \gamma)-\Delta r_{a} / \gamma-r_{a}}$

where $\lambda$ is the latent heat of vaporization of water $(2465 \mathrm{~kJ} / \mathrm{kg}), \gamma$ is the psychrometric constant $(65.5 \mathrm{~Pa} / \mathrm{K}), \rho$ is the density of the air $\left(1.25 \mathrm{~kg} \mathrm{~m}^{-3}\right), \mathrm{r}_{\mathrm{a}}\left(\mathrm{s} \mathrm{m}^{-1}\right)$ is the aerodynamic resistance calculated from the logarithmic wind profile for the neutral condition per (She et al., 2013; Sommer et al., 2002; Whitley et al., 2009), $C_{p}$ is the specific heat of air $\left(1010 \mathrm{Jkg}^{-1} \mathrm{~K}^{-1}\right)$, and VPD is the vapour pressure deficit of the canopy air (Chang et al., 2006), calculated by the Campbell equation (Campbell and Norman, 1998; Li et al., 2013, 2010):

$V P D_{i}=\left(1-R H_{i}\right) \times 0.6108 \times \exp \left(\frac{17.27 T}{T+237.3}\right)$

where $\mathrm{RH}$ is the relative humidity (\%), and $\mathrm{T}$ is the air temperature $\left({ }^{\circ} \mathrm{C}\right)$.

\subsection{Modelling}

\subsubsection{Canopy transpiration}

The Penman-Monteith equation was used to estimate the Populus simonii Carr canopy transpiration $\left(E_{c}^{\text {pred }}, \mathrm{mm} \mathrm{s}^{-1}\right.$ ) (Han et al., 2011; She et al., 2013; Yunusa et al., 2000).

$E_{c}^{\text {pred }}=\frac{\Delta\left(R_{n}-G\right)+\rho C_{P} V P D g_{a}}{\lambda\left[\Delta+\gamma\left(1+g_{a} / g_{c}^{\text {pred }}\right)\right]}$

where $\Delta\left(\mathrm{Pa} \mathrm{K}^{-1}\right)$ is the slope of the relationship between the saturation vapour pressure and temperature (Zeppel et al., 2008), $\mathrm{G}$ is the heat flux to the soil $\left(\mathrm{W} \mathrm{m}^{-2}\right), R n$ is the solar radiation above the forest canopy $\left(\mathrm{W} \mathrm{m}^{-2}\right), \mathrm{g}_{\mathrm{a}}$ is the aerodynamic conductance $\left(\mathrm{m} \mathrm{s}^{-1}\right.$ ) (She et al., 2013; Sommer et al., 2002; Whitley et al., 2009), and $g_{c}^{\text {pred }}$ is the predicted canopy conductance $\left(\mathrm{m} \mathrm{s}^{-1}\right)$.

\subsubsection{Canopy conductance}

The modelling approach is based on the work of Jarvis (Jarvis and McNaughton, 1986), wherein the canopy conductance is separable and parameterized as a multiple response of the leaf stomatal resistance to environmental factors (Sommer et al., 2002). The canopy conductance $\left(\mathrm{g}_{\mathrm{c}}, \mathrm{m} \mathrm{s}^{-1}\right)$ is modelled by response functions ( $\mathrm{f}, 0 \leq f \leq 1$ ). In the study, $\mathrm{g}_{\mathrm{c}}$ is assumed to be determined by VPD, $\mathrm{R}_{\mathrm{n}}$ and the soil moisture $(\theta)$ (Jarvis and McNaughton, 1986), which is modified as

$g_{c}^{\text {pred }}=g_{\text {cMax }} \operatorname{LAIf}(R n) f(V P D) f(\theta)$

where $\mathrm{g}_{\mathrm{cMax}}$ is the maximum canopy conductance and $f\left(R_{n}\right) f(V P D)$ and $f(\theta)$ are the limiting functions of $\mathrm{R}_{\mathrm{n}}$, VPD and the soil moisture $(\theta)$, respectively,

$$
\begin{aligned}
& f(R n)=\frac{R_{n} \times\left(R_{n H}+k_{1}\right)}{R_{n H} \times\left(k_{1}+R_{n}\right)} \\
& f(V P D)=k_{2} 1 \mathrm{n}(V P D)+k_{3} \\
& f(\theta)=\frac{1}{1+\left(\theta_{r} / \theta_{0}\right)^{-k_{4}}} \\
& \theta_{r}=\left(\theta-\theta_{w}\right) /\left(\theta_{\text {fld }}-\theta_{w}\right)
\end{aligned}
$$

in which $R_{n H}$ is the approximate maximum solar radiation, assumed to be $400\left(\mathrm{~W} \mathrm{~m}^{-2}\right)$ for daily step calculations according to the measurements; $\mathrm{k}_{1}$ is a fitted parameter (Wang et al., 2014; Whitley et al., 2013); $\theta_{r}$ is the relative extractable water (REW) in the soil; $\theta_{w}$ is the wilting point; $\theta_{f l d}$ is the soil water field capacity; $\theta_{0}=0.38$ when $f(\theta)=0.5$; and $\mathrm{k}_{1}, \mathrm{k}_{2}, \mathrm{k}_{3}$ and $\mathrm{k}_{4}$ are parameters identified by data measurements.

\subsection{Calibration and verification}

The predicted $g_{c}$ and $E_{c}$ values were graphically compared with the measured values and determined to be robust and consistent (Lu et al., 2003). The root mean square error (RMSE) was used to weight the deviation between the ith experimental value $\left(\mathrm{y}_{\mathrm{i}}\right)$ and the ith predicted value $\left(\hat{y}_{i}\right)$ of $g_{c}\left(E_{c}\right)$, where we express the RMSE as

$R M S E=\left[\frac{1}{n} \sum\left(y_{i}-\hat{y}_{i}\right)^{2}\right]^{1 / 2}$

In addition to the aforementioned data processing procedure, statistical analyses were conducted using the SPSS software package (version 19.0 for Windows, SPSS Inc., USA) to determine the model that links the canopy conductance to VPD, $\mathrm{R}_{\mathrm{n}}$, and $\theta_{r}$. All statistical analyses were performed using SPSS software with $\alpha=0.05$ as the threshold for statistical significance.

\section{Results and discussion}

\subsection{Microclimate and soil moisture}

Variations in the weather during the tree-growing season in 2014 are shown in Figs. 3 and 4. The monthly temperatures from May to August during the experiment year increased, but they decreased from September to October. During the experimental period, the total rainfall was $75.5 \mathrm{~mm}$. The relative humidity was higher in June than in August or September, and the VPD was inverted. The mean daily temperature was $19.6( \pm 5)^{\circ} \mathrm{C}$, with a minimum of $1{ }^{\circ} \mathrm{C}$ and a maximum of $32^{\circ} \mathrm{C}$. The mean daily VPD was 1.7 $( \pm 0.3) \mathrm{kPa}$, with a maximum of $3.5 \mathrm{kPa}$. The variations of the soil

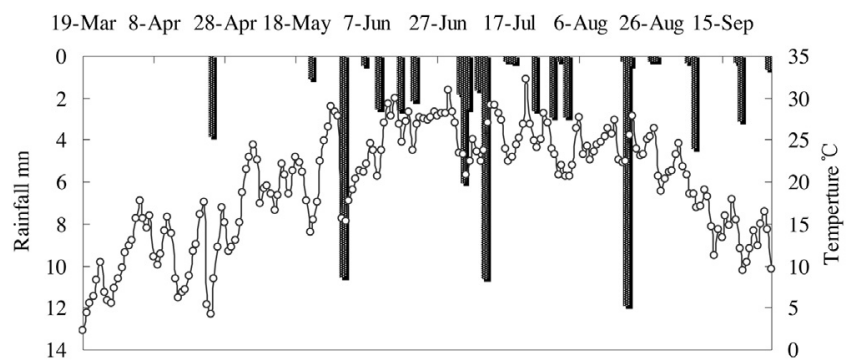

Fig. 3. Environmental conditions during the 2014 growing season. Mean daily air temperature (line, ${ }^{\circ} \mathrm{C}$ ) and daily precipitation ( $\mathrm{mm}$ ).

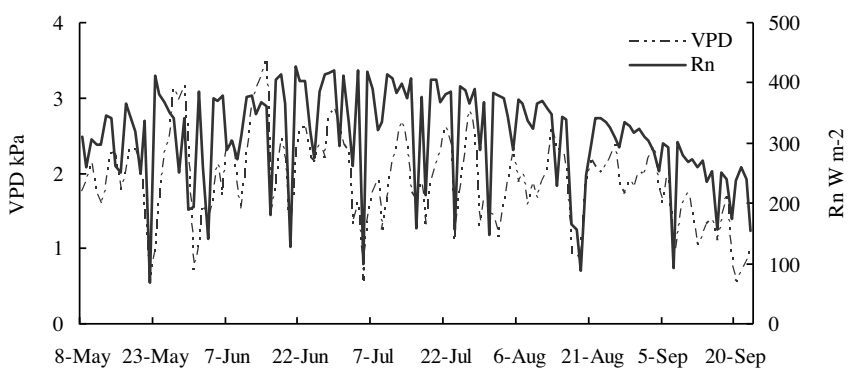

Fig. 4. Environmental conditions from May 2014 to September 2014 (VPD, $R_{n}$ ). 
water content $1.5 \mathrm{~m}$ underneath the surface are shown in Fig. 5. The relative extractable water was $0.53( \pm 0.06)$ at $20 \mathrm{~cm}, 0.29( \pm 0.05)$ at $40 \mathrm{~cm}, 0.49( \pm 0.05)$ at $90 \mathrm{~cm}$, and $0.72( \pm 0.05)$ at $150 \mathrm{~cm}$ soil depth throughout the experimental period. The soil moisture experienced its largest variations in the upper $90 \mathrm{~cm}$, especially during low rainfall periods (Fig. 5). It decreased as the depth increases from 0 to $40 \mathrm{~cm}$ and increased as the depth increased from 50 to $150 \mathrm{~cm}$. The surface soil water content sharply decreased in June and was stable from August to September (Fig. 5). The decline in the soil moisture content during this period was reflected by the water uptake by trees. However, the cause of this result was not only soil water evaporation but also tree transpiration. Two periods of irrigation were carried out in the study plot (Fig. 5), and the soil water content greatly changed in the upper $90 \mathrm{~cm}$.

\subsection{Stand structural characters}

According to measured sapwood radius (SR) and heartwood radius (HR), the sapwood area $\left(A_{s w}\right)$ could calculated by $A_{S W}=$ $\pi \times\left[(S R+H R)^{2}-H R^{2}\right]$. The individual $A_{s w}$ was determined from the increment cores, and then the stand sapwood area was obtained by the regression of the DBH- $\mathrm{A}_{\mathrm{sw}}$ relationship (Eq. (13)). Based on this relationship and the tree distribution per ha with respect to the $\mathrm{DBH}$, the daily $\operatorname{Tr}$ was calculated by integrating the actual $\mathrm{E}_{\mathrm{c}}$ for each day over all the DBH classes (Brito et al., 2014).

$$
\mathrm{A}_{\mathrm{sw}}=6.6308 \times \mathrm{e}^{0.1566 \times \mathrm{DBH}}, \quad \mathrm{R}^{2}=0.9774, \quad \mathrm{n}=8\left(\mathrm{~A}_{\mathrm{sw}}: \mathrm{m}^{2}, \mathrm{DBH}: \mathrm{cm}\right)
$$

The canopy areas were calculated by conical surfaces, and a regression was obtained between the canopy area and the $\mathrm{DBH}$. Based on this relation and the tree age with respect to the $\mathrm{DBH}$, the tree canopy areas of different stand ages could be calculated.

$$
\mathrm{A}_{\text {canopy }}=8.0143 \times \ln (\mathrm{DBH})+1.5828, \quad \mathrm{R}^{2}=0.8776, \quad\left(\mathrm{~A}_{\text {canopy }}: \mathrm{m}^{2}, \mathrm{DBH}: \mathrm{cm}\right)
$$

The measured DBH values for different stand ages were used to obtain the regression function from the sample trees:

$\mathrm{DBH}=8.489 \times \ln (\mathrm{x})-8.84 \quad \mathrm{R}^{2}=0.928, \quad(\mathrm{DBH}: \mathrm{cm}, \mathrm{X}:$ stand age $)$

From the above equations, the tree sapwood area and canopy area increased with the $\mathrm{DBH}$, which increases with the stand age. The canopy area peaked at $25 \mathrm{~m}^{2}$ and then stabilized during the mature period. The DBH continued to grow, quickly in the young period, slowly in the immature period, and reaching a peak in the mature period. Using these equations, the tree sapwood area, canopy area and DBH from young trees to mature trees could be estimated.

\subsection{Canopy transpiration and canopy conductance}

The canopy transpiration and canopy conductance varied considerably on a seasonal cycle (Fig. 6). The canopy transpiration

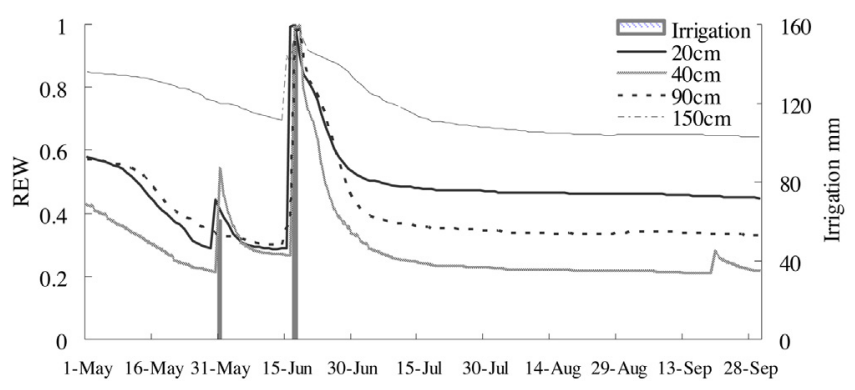

Fig. 5. Relative extractable water at different depths. varied between $0.5 \mathrm{~mm} \mathrm{day}^{-1}$ during cloudless days, with a high evaporative demand and ample soil water availability, and it was close to 0.1 during the hot and dry summer (Fig. 6a). The total annual canopy transpiration was $31.5 \mathrm{~mm}$, with $75 \%$ occurring during the cold and wet period, when the soil water was not limited.

A similar seasonal trend was observed for $g_{c}$ (Fig. 6b), with maximum values up to $0.6 \mathrm{~mm} \mathrm{~s}^{-1}$ (May 12, 2014), when the soil water availability was not limited, and it reached minimum values close to $0.1 \mathrm{~mm} \mathrm{~s}^{-1}$ under conditions of soil drought (Fig. 4).

\subsection{Model calibration and verification}

A careful check suggests that this result is because some extreme large conductance values were accidentally allocated to the training data set. The period from May to June was applied for model calibration and later for model verification, parameters were showed in Table 2. The results showed a consistent overestimation of the measured canopy conductance at night for these two periods (Fig. 7 , a: calibration; b: verification). In the model, $g_{c}$ is a hyperbolic curve with $R_{n}$, and the value of $R_{n}$ at night is zero; therefore, the modelled value at night is zero. However, in fact, there was still sap flow at night; thus, the conductance was above zero (Zweifel and Häsler, 2001).

The canopy transpiration rate is shown in Fig. 6, and the daily stand transpiration could be calculated from $E_{\text {day }}=E_{c} \times A_{\text {canopy }} / A_{\text {stand }}$. The measured hourly (dashed regression line) stand transpiration of the Populus simonii Carr shelterbelt was compared to the estimated values (solid regression line) (Fig. 8). From May to June, the hourly measured transpiration was larger than the modelled transpiration (Fig. 8a) at noon, but the daily transpiration stayed the same (Fig. 8). In July, the modelled hourly transpiration at noon was higher than the measured hourly transpiration at noon, and the modelled daily transpiration was also higher than the measured daily transpiration (Fig. 8b). There was little deviation between the measured and modelled daily transpirations. The daily transpiration was fit by a regression to $\mathrm{y}=1.0513 \mathrm{x}-0.0021$, and the $\mathrm{R}^{2}$ was 0.81 ( $\mathrm{y}$ is the measured transpiration and $\mathrm{x}$ is the modelled transpiration).

The correlation coefficient ( $r$ ), root-mean-square error (RMSE), and slope of the linear regression were determined to evaluate the
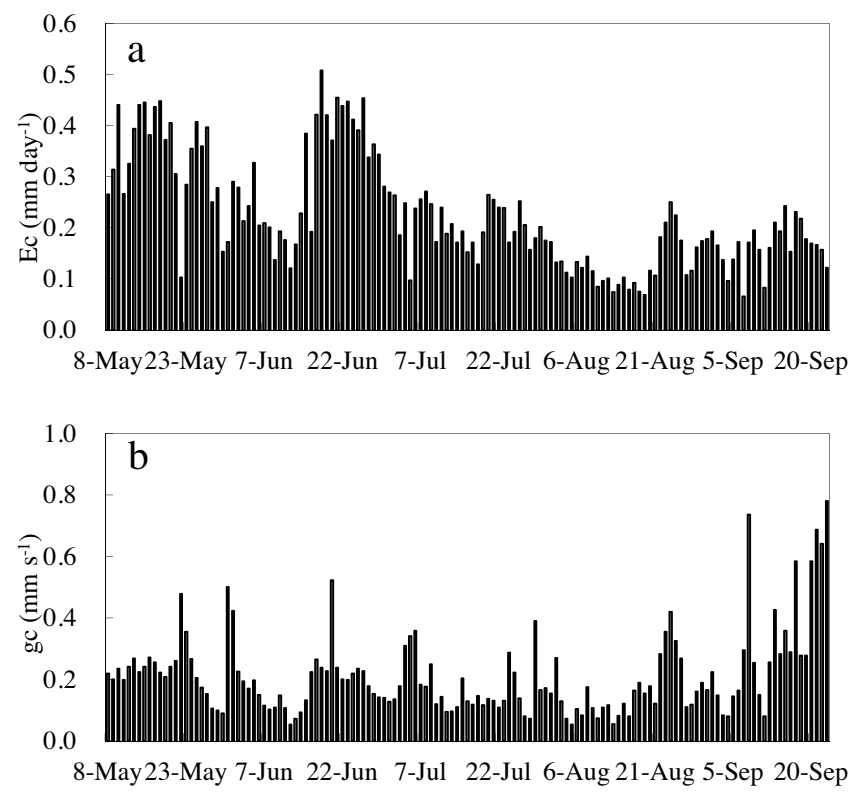

Fig. 6. Seasonal course of daily canopy transpiration and the mean daily canopy conductance between May 1, 2014 and October 20, 2014. 
Table 2

Parameters of the model.

\begin{tabular}{lllll}
\hline & $\mathrm{k} 1$ & $\mathrm{k} 2$ & $\mathrm{k} 3$ & $\mathrm{k} 4$ \\
\hline Parameter Values & 0.025 & -0.13 & 0.27 & -15.23
\end{tabular}

effectiveness of the model (Table 3 ). For the canopy conductance, the slope was 0.976 , and $\mathrm{R}^{2}=0.79$, which indicates that the model was well fit in the study. As verified from the transpiration, the model generally fit the measured data well, with a slope of 1.05 and an $\mathrm{R}^{2}$ of 0.81 .

Although the model performed well in this study area, there was some deviation. Most of the deviation occurred at night, probably because intense transpiration results in a water deficit in living organisms during the daytime. To recover the water balance, soil water enters via root pressure during the night. For example, the nightly contribution of the sapwood to soil water exceeds $1 \mathrm{~mm}$ per day of transpiration (Zweifel and Häsler, 2001). In May, the modelled transpiration was slightly lower than the measured stand sap flow, possibly because young leaves, even if fully expanded, had not yet reached physiological maturity and were thus severely affected by soil water stress (Kume et al., 2007). However, in July, the modelled transpiration was larger than the actual measurements, which can be attributed to the non-involvement of the temperature response function in the model. High temperatures coupled with strong solar radiation and low air humidity can limit the plants' physiological activity and transpiration (Zhou et al., 2004).

A higher atmospheric evaporative demand and lower soil moisture influences the trees' sap flow and canopy conductance (Kume et al., 2007). The REW and VPD were usually used as indexes to identify soil water stress and atmospheric drought. The effect of soil water stress on vegetation has been a significant research topic in recent years. The REW varies between 0 and 1 , and the soil moisture conditions are defined as stressed when the REW is below 0.4 (Breda et al., 2006; Chen et al., 2014). The soil was considered to be under a more severe drought when the values of REW were less. The summer was particularly dry (precipitation of $74.5 \mathrm{~mm}$ during the study period) and hot (mean $\mathrm{T}>23^{\circ} \mathrm{C}$ each month) in 2014. While the soil was progressively drying during the vegetation period, the REW quickly decreased from the surface to a depth $90 \mathrm{~cm}$ and dropped below the threshold of 0.4 in early July. Below this threshold, trees are known to suffer from water stress (Bernier et al., 2002; Granier et al., 1999). In the farmland shelterbelt, the REW was below 0.4 for a long time during the growing season. By contrast, the tree conductance logistic increased from the wilt point to the field capacity. The tree conductance changed little with no water stress, and when the relative extractable water exceeds 0.4 (She et al., 2013), changing in a similar manner to the transpiration. Populus simonii Carr trees close their leaf stoma to cut water loss when suffering water stress; therefore, the $g_{c}$ and transpiration decreased as the water stress increased. Both the daytime and night-time transpiration decreased as the soil drought increased, but they increased as the atmospheric drought increased.

In contrast to the relatively simple relationship linking REW and $E_{c}$ and $g_{c}$, the relationship between $E_{c}, g_{c}$ and VPD was more complex. The function relating $E_{c}, g_{c}$ and VPD was determined by both the direct response of the stoma to VPD and the response of diffusion to VPD (Whitley et al., 2009). VPD is an atmospheric drought index (Naithani et al., 2012). When the VPD decreases, the atmosphere drought increases, and vice versa. The threshold of $2-3 \mathrm{kPa}$ for declining transpiration with increasing VPD observed in the present study is larger than that observed by Komatsu et al. (2006). This difference is probably because the site used in the present study is much drier and thus experiences a much larger range of VPD. The response of the stomata to VPD is strongly influenced by the soil moisture content (Whitley et al., 2009), and therefore, the long-term drought experienced at the present site was likely to have influenced the response we observed. Hence, soil drought and atmospheric drought had a synergistic effect on farmland shelterbelt transpiration. Both the tree growing character and meteorological factors were considered in the model. We conclude that compared to using sap flow records alone, the simultaneous
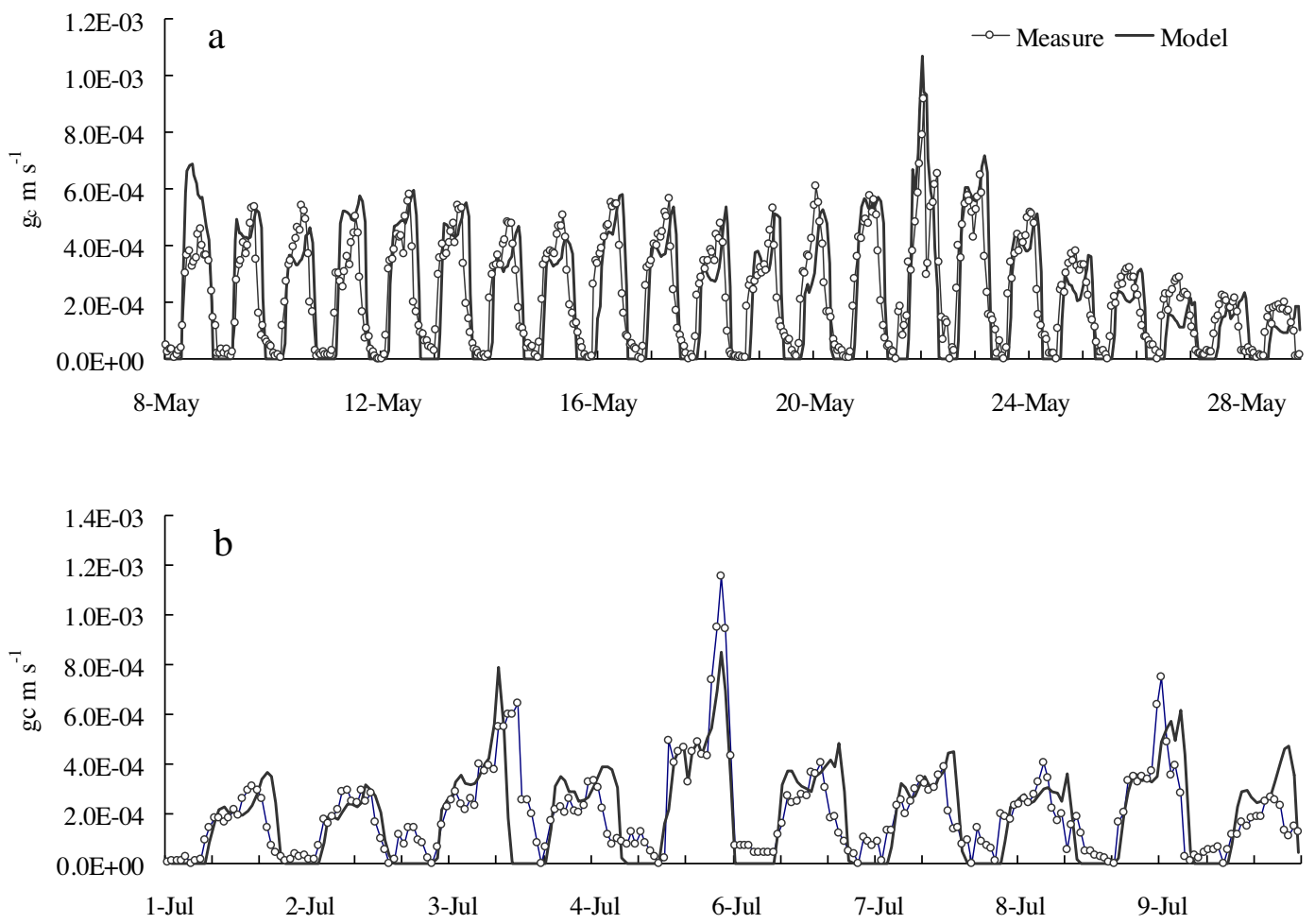

Fig. 7. Comparison of the measured hourly canopy conductance (dashed regression line) to the estimated during the growing period (a: calibration b: verification). 

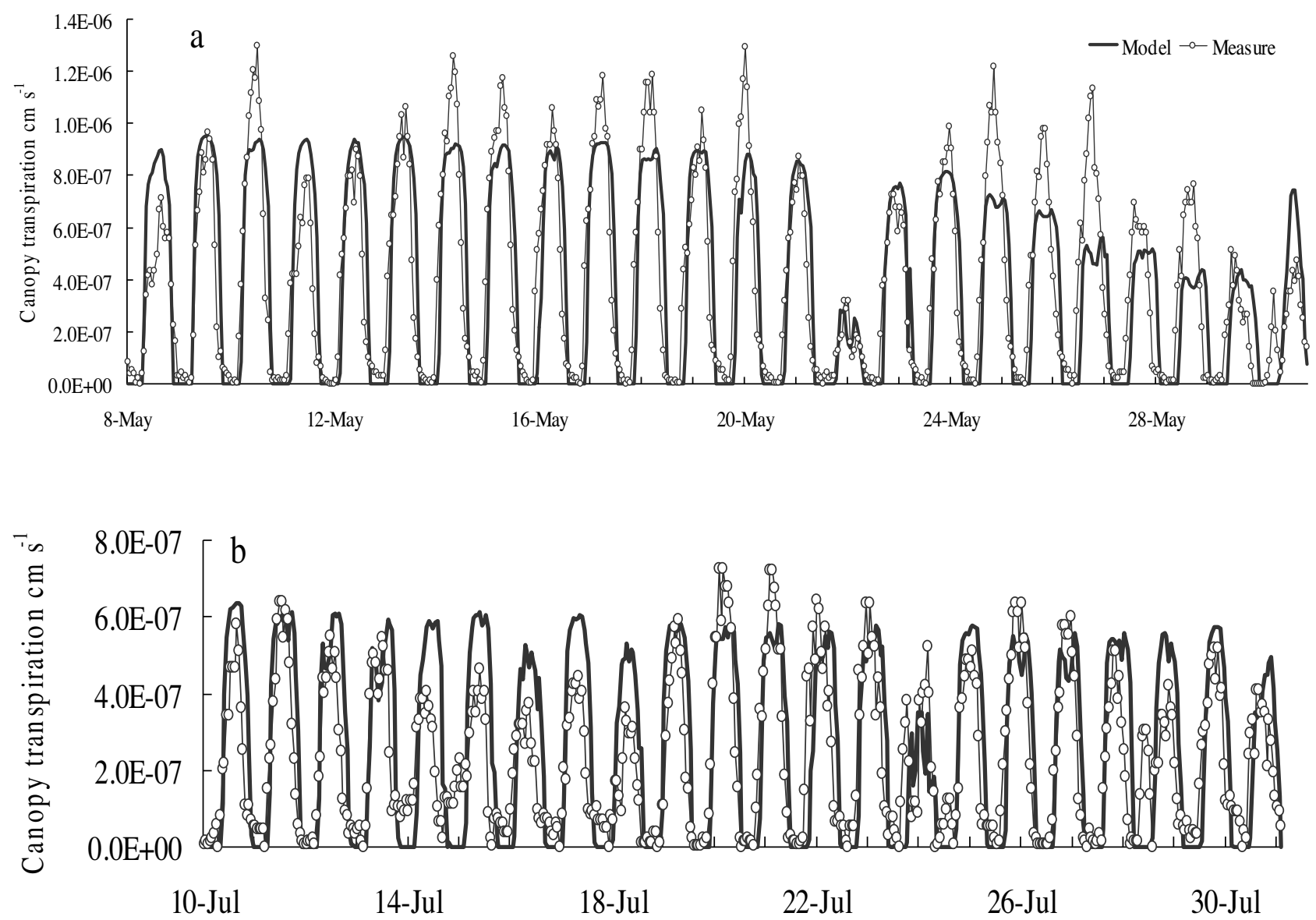

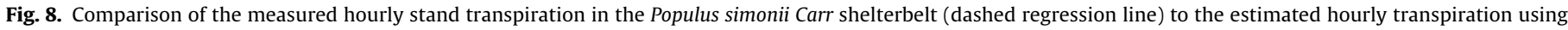
the submodel calibrated in the Mosuowan experimental plot (solid regression line).

Table 3

Regression statistics for the model that were applied at the site. The slope (m) and intercept (c) of the regression line, the explained variance $\left(\mathrm{R}^{2}\right)$, and the root meansquare error (RMSE) are listed.

\begin{tabular}{lll}
\hline & $\mathrm{g}_{\mathrm{c}}\left(\mathrm{m} \mathrm{s}^{-1}\right)$ & Canopy transpiration $(\mathrm{cm} /$ day $)$ \\
\hline $\mathrm{m}$ & 0.976 & 1.0513 \\
$\mathrm{c}$ & 0.0002 & 0.0021 \\
$\mathrm{R}^{2}$ & 0.79 & 0.81 \\
$\mathrm{RMSE}$ & $9.45 \times 10^{-4}$ & $6.39 \times 10^{-3}$ \\
$\mathrm{~N}$ & 1520 & 140 \\
\hline
\end{tabular}

use of sap flow and model values provides more detailed information to assess water needs in farmland shelterbelts.

\subsection{Assessment of water needs}

\subsubsection{Response of water needs to water stress}

The model performed well in the canopy conductance and transpiration estimations. The stand transpiration under different water stresses was needed to calculate the required irrigation. The SFD occurred during the day and the night, and it increased in absolute magnitude with the increasing atmospheric drought and declined as the soil drought increased. When the drought was at its worst, no sap flow could be detected in the trees. On average, transpiration stopped when $80 \%$ of the relative extractable water in the rooting zone had been depleted (Lagergren and Lindroth, 2002). Under different soil water contents, the transpiration of the Populus simonii Carr tree was different. The soil moisture influences the LAI and the whole tree transpiration. We assumed that the REW was maintained at one level during the growing season and estimated the tree transpiration under different soil moisture levels. Fig. 9 shows that there was micro transpiration when the REW was 0.2 , and the transpiration was $0.06 \mathrm{~cm} /$ day at $\mathrm{REW}=0.3$. This result agrees with recent research (Lagergren and Lindroth, 2002) showing that no sap flow was detected when $80 \%$ of the relative extractable water in the rooting zone had been depleted. The transpiration significantly changed when the REW ranged from 0.3 to 0.4 . The soil moisture conditions were defined as stressed when the REW ranged below 0.4 (Breda et al., 2006; Chen et al., 2014). The transpiration increased as the REW rose (Fernandez et al., 2011) and followed a S logistic equation: $\mathrm{y}=1 /\left[1+\mathrm{e}^{-60.67 \times(\mathrm{REW}-0.402)}\right]\left(\mathrm{R}^{2}=0.98\right)$ showed in Fig. 10. With no water stress, the transpiration may reach $170 \mathrm{~mm}, 333 \mathrm{~mm}$, $307 \mathrm{~mm}, 263 \mathrm{~mm}$ and $65 \mathrm{~mm} / \mathrm{month}$ from May to September. And stand transpiration was $98.5 \mathrm{~mm}, 172 \mathrm{~mm}, 170 \mathrm{~mm}, 106 \mathrm{~mm}$ and $30 \mathrm{~mm}$ from May to September under REW $=0.4$, respectively. To keep the farmland shelterbelt away from water stress in 2014, $67 \mathrm{~mm}, 133 \mathrm{~mm}, 141 \mathrm{~mm}, 79 \mathrm{~mm}$ and $15 \mathrm{~mm}$ of irrigation were needed for each month from May to September, respectively.

In 2014, the transpiration was close to the sum of the precipitation, and changes in the soil water storage were only shown in May. The total precipitation $(\mathrm{mm})$ and runoff $(\mathrm{mm})$ in May were $11.4 \mathrm{~mm}$, the irrigation was $0 \mathrm{~mm}$, the change in soil water storage was $50.78 \mathrm{~mm}$, and the transpiration was $66 \mathrm{~mm}$. The gap between the transpiration and the precipitation became larger in the later months. We ignored bare soil evaporation in the analysis; thus, the shelterbelt transpiration must come from a deep supply. In addition to these factors, groundwater is also an important cause of 


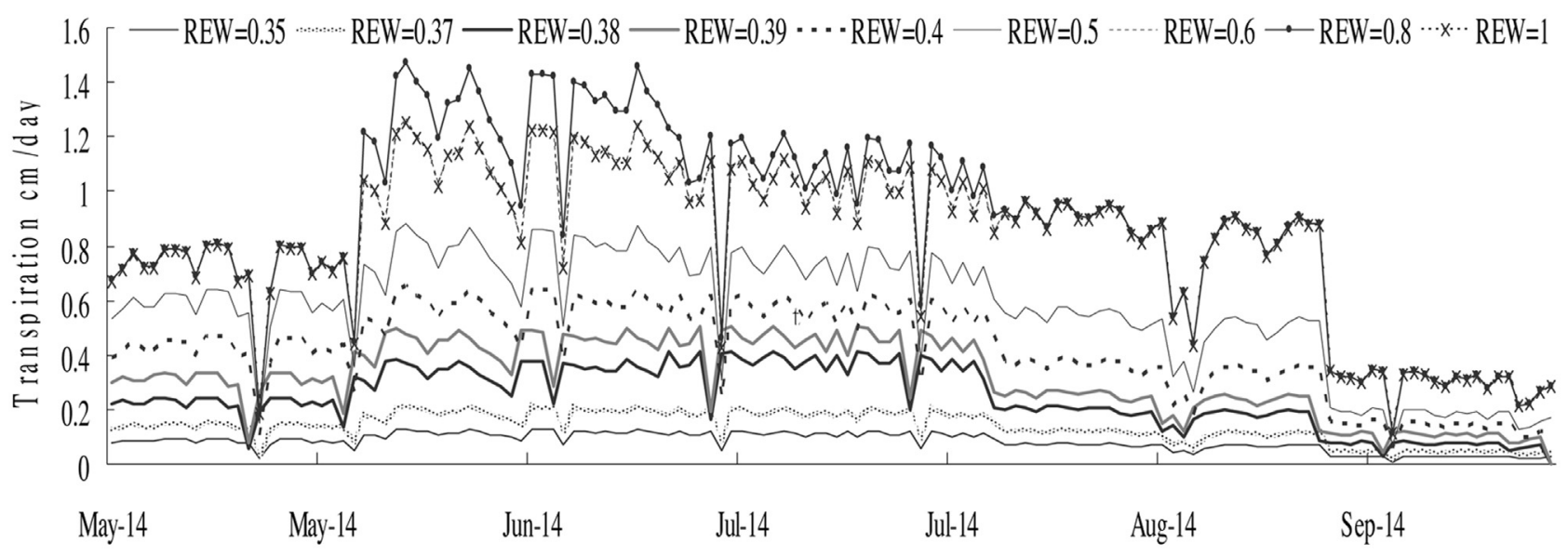

Fig. 9. Comparison of the estimated daily stand transpiration in the Populus simonii Carr shelterbelt under different soil moisture levels.

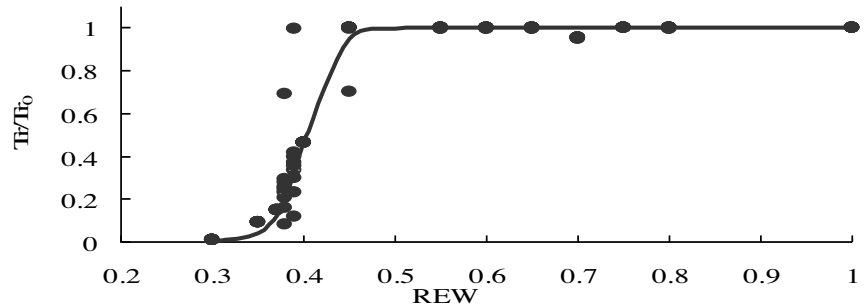

Fig. 10. Relationship between the transpiration and the REW $\left(\operatorname{Tr} / \operatorname{Tr}_{0}\right.$ : the rate of $\operatorname{Tr}$ to $\mathrm{Tr}_{0}$; $\operatorname{Tr}$ : transpiration at various $\mathrm{REW} ; \mathrm{Tr}_{0}$ : transpiration at $\mathrm{REW}=1$; REW: relative extractable water in the soil).

tree transpiration. In the present study, free water released from the groundwater decline (release) is calculated by the equation $E T=\mu \Delta h$. When $\mu$ is 0.05 , the $\Delta h$ of groundwater declines (Shen et al., 1999). In the study area, drip irrigation was most often used, and the groundwater quickly declined in the growing season (April to September). Hence, the transpiration supply by groundwater needs further research.

\subsubsection{Response of water needs to stand age}

The threshold of tree transpiration in different stand ages is necessary to protect farmland shelterbelts. The transpiration at the water stress point $(\mathrm{REW}=0.4$ ) was calculated for young trees to mature trees. The farmland shelterbelt considered was built in 1980 with three-year-old Populus simonii Carr trees. We defined three periods based on the stand ages: young ( $0-10$ years), immature (10-20 years) and mature (above 20 years). The transpiration results are shown in Figs. 11 and 12 . In the young period, the transpiration was $2.77 \pm 1.31,4.31 \pm 1.53,4.3 \pm 2.3,3.01 \pm 1.46$ and $0.75 \pm 0.42 \mathrm{~cm}$ for each month from May to September, respectively, and the values were $10.67 \pm 1.36,16.32 \pm 1.55,15.94 \pm 3.30$, $11.46 \pm 2.50$ and $2.87 \pm 0.75 \mathrm{~cm}$ for each month in the immature period. In the mature period, the transpiration was higher than in the other phases: $21.33 \pm 3,31.98 \pm 4.5,31.87 \pm 4.92$, $22.22 \pm 3.46$ and $5.78 \pm 0.61 \mathrm{~cm}$ for each month from May to September. The stand transpiration of the whole growing season was $16.69 \pm 5.1 \mathrm{~cm} /$ year in the young period, $62.5 \pm 8.2 \mathrm{~cm} /$ year in the immature period, and $116.7 \pm 16 \mathrm{~cm} /$ year in the mature. The values were near those experimentally determined in the plot (Shi et al., 2011). When the trees were young, the stand transpiration was small and slowly increased. In the immature trees, it quickly increased as the stand ages rose, and it rarely increased in the mature period. The changes followed a logistic equation increasing with the tree age, $y=847-844 /\left[1+(x / 87.9)^{1.9}\right]\left(R^{2}=0.98, y\right.$ : $\mathrm{cm} /$ year, $\mathrm{x}$ : tree ages). These results can help managers determine the farmland shelterbelt stand transpiration under different levels of water stress and provide details for the transpiration of different stand age farmland shelterbelts.

\section{Conclusions}

For a farmland shelterbelt of Populus simonii Carr trees with high water consumption in a soil with a medium to high water holding capacity, the signal intensity approach for sap flow shows poor reliability for detecting water stress in deficit-irrigated trees. Knowledge of the physiological behaviour of the species must be taken into account for interpreting transpiration records, especially when the atmospheric and soil moisture changes, when recovery irrigations are applied. The model was useful to indicate the water needs, and the severity, the water stress and the species physiology are taken into account. The time course of the water needs showed that the occurrence of water stress in the farmland shelterbelt trees had a large impact on its water consumption because the water consumption increased as the water stress decreased, following

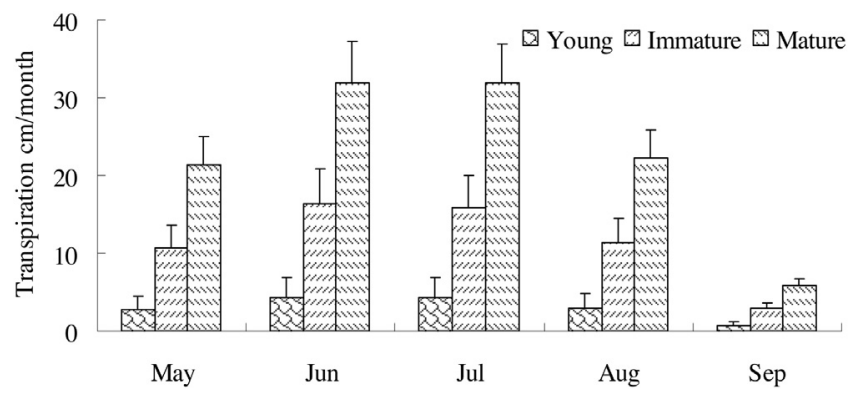

Fig. 11. Monthly transpiration of young, immature and mature growth periods.

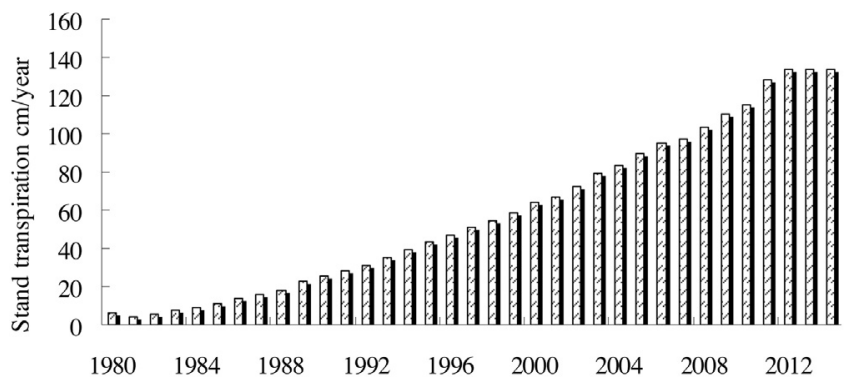

Fig. 12. Stand transpiration of growing season from 1980 to 2014. 
the equation $y=1 /\left[1+\mathrm{e}^{-60.67 \times(\mathrm{REW}-0.402)}\right]$. The simultaneous use of the model and the tree structure increases the reliability of the assessment of water needs from young to mature. Improving the recognition of plant water consumption has important significance for farmland shelterbelt protection. Future research is needed to confirm these results and analyse the influence of groundwater and the atmosphere.

\section{Acknowledgments}

This study was financially supported by the National Natural Science Foundation of China (41371115; 41390461).

\section{References}

Anderegg, W.R.L., Berry, J.A., Field, C.B., 2012. Linking definitions, mechanisms, and modeling of drought-induced tree death. Trends Plant Sci. 17, 693-700.

Anderegg, W.R.L., Kane, J.M., Anderegg, L.D.L., 2013. Consequences of widespread tree mortality triggered by drought and temperature stress. Nat. Clim. Change 3, 30-36.

Bernier, P., Bréda, N., Granier, A., Raulier, F., Mathieu, F., 2002. Validation of a canopy gas exchange model and derivation of a soil water modifier for transpiration for sugar maple (Acer saccharumMarsh.) using sap flow density measurements. For. Ecol. Manage. 163, 185-196.

Bonan, G.B., 2008. Forests and climate change: forcings, feedbacks, and the climate benefits of forests. Science 320, 1444-1449.

Breda, N., Huc, R., Granier, A., Dreyer, E., 2006. Temperate forest trees and stands under severe drought: a review of ecophysiological responses, adaptation processes and long-term consequences. Ann. For. Sci. 63, 625-644.

Brito, P., Lorenzo, J.R., Gonzalez-Rodriguez, A.M., Morales, D., Wieser, G., Jimenez, M.S., 2014. Canopy transpiration of a Pinus canariensis forest at the tree line: implications for its distribution under predicted climate warming. Eur. J. For. Res. 133, 491-500.

Campbell, G.S., Norman, J.M., 1998. An introduction to environmental biophysics, Second edition. Springer, New York, pp.53-140.

Cermak, J., Kucera, J., Nadezhdina, N., 2004. Sap flow measurements with some thermodynamic methods, flow integration within trees and scaling up from sample trees to entire forest stands. Trees Struct. Funct. 18, 529-546.

Chang, X., Zhao, W., Zhang, Z., Su, Y., 2006. Sap flow and tree conductance of shelter-belt in arid region of China. Agric. For. Meteorol. 138, 132-141.

Chen, L., Wei, W., Fu, B., Lü, Y., 2007. Soil and water conservation on the Loess Plateau in China: review and perspective. Prog. Phys. Geogr. 31, 389-403.

Chen, H., Shao, M., Li, Y., 2008. Soil desiccation in the loess plateau of China. Geoderma 143, 91-100.

Chen, L.X., Zhang, Z.Q., Ewers, B.E., 2012. Urban tree species show the same hydraulic response to vapor pressure deficit across varying tree size and environmental conditions. PLoS One 7.

Chen, L.X., Zhang, Z.Q., Zha, T.G., Mo, K.L., Zhang, Y., Fang, X.R., 2014. Soil water affects transpiration response to rainfall and vapor pressure deficit in poplar plantation. New For. 45, 235-250.

Dong, X., Zhang, Y., Cui, W., Xun, B., Yu, B., Ulgiati, S., Zhang, X., 2011. Emergy-based adjustment of the agricultural structure in a low-carbon economy in manas county of China. Energies 4, 1428-1442.

Fan, Z.P., Zeng, D.H., Zhu, J.J., Jiang, F.Q., Yu, X.X., 2002. Advance in characteristics of ecological effects of farmland shelterbelts. J. Soil Water Conserv., 130-133.

Fernandez, J.E., Moreno, F., Martin-Palomo, M.J., Cuevas, M.V., Torres-Ruiz, J.M., Moriana, A., 2011. Combining sap flow and trunk diameter measurements to assess water needs in mature olive orchards. Environ. Exp. Bot. 72, 330-338.

Gharun, M., Turnbull, T.L., Adams, M.A., 2013. Validation of canopy transpiration in a mixed-species foothill eucalypt forest using a soil-plant-atmosphere model. J. Hydrol. 492, 219-227.

Granier, A., Loustau, D., 1994. Measuring and modeling the transpiration of a maritime pine canopy from sapflow data. Agric. For. Meteorol. 71, 61-81.

Granier, A., Bréda, N., Biron, P., Villette, S., 1999. A lumped water balance model to evaluate duration and intensity of drought constraints in forest stands. Ecol. Model. 116, 269-283.

Granier, A., 1987. Evaluation of transpiration in a Douglas-fir stand by means of sap flow measurements. Tree Physiol. 3, 309-320.

Han, L., He, K.N., Hu, X.B., Zhang, D., Qin, J., Dong, M., Li, A.C., 2011. Characteristics and modelling of canopy conductance and transpiration of Platycladus orientalis (L.) Franco in Loess Plateau of China. Afr. J. Agric. Res. 6, 4253-4260.

Han, L., He, K., Hu, X., Zhang, D., 2012. Canopy transpirantion response to environmental variations in Platycladus orientalis: properties and modelling. Pak. J. Bot. 44, 541-545.

Jarvis, P.G., McNaughton, K.G., 1986. Stomatal control of transpiration scaling up from leaf to region. Adv. Ecol. Res. 15, 1-49.

Jarvis, P., 1976. The interpretation of the variations in leaf water potential and stomatal conductance found in canopies in the field. Philos. Trans. R. Soc. Lond. B: Biol. Sci. 273, 593-610.
Jonard, F., Andre, F., Ponette, Q., Vincke, C., Jonard, M., 2011. Sap flux density and stomatal conductance of European beech and common oak trees in pure and mixed stands during the summer drought of 2003. J. Hydrol. 409, 371-381.

Jung, E.Y., Otieno, D., Kwon, H., Berger, S., Hauer, M., Tenhunen, J., 2014. Influence of elevation on canopy transpiration of temperate deciduous forests in a complex mountainous terrain of South Korea. Plant Soil 378, 153-172.

Kang, Y., Wang, R., Wan, S., Hu, W., Jiang, S., Liu, S., 2012. Effects of different water levels on cotton growth and water use through drip irrigation in an arid region with saline ground water of Northwest China. Agric. Water Manage. 109, $117-126$.

Komatsu, H., Kang, Y., Kume, T., Yoshifuji, N., Hotta, N., 2006. Transpiration from a Cryptomeria japonica plantation, part 2: responses of canopy conductance to meteorological factors. Hydrol. Processes 20, 1321-1334.

Kumagai, T., Aoki, S., Nagasawa, H., Mabuchi, T., Kubota, K., Inoue, S., Utsumi, Y., Otsuki, K., 2005. Effects of tree-to-tree and radial variations on sap flow estimates of transpiration in Japanese cedar. Agric. For. Meteorol. 135, $110-116$.

Kume, T., Takizawa, H., Yoshifuji, N., Tanaka, K., Tantasirin, C., Tanaka, N., Suzuki, M., 2007. Impact of soil drought on sap flow and water status of evergreen trees in a tropical monsoon forest in northern Thailand. For. Ecol. Manage. 238 220-230.

Lagergren, F., Lindroth, A., 2002. Transpiration response to soil moisture in pine and spruce trees in Sweden. Agric. For. Meteorol. 112, 67-85.

Li, X.Y., Yang, P.L., Ren, S.M., Ren, L., 2010. Characteristics and simulation of canopy conductnce of cherry. Acta Ecol. Sin., 300-308.

Li, W., SiJ.H. Feng, Q., Yu, T.F., 2013. Response of transpiration to water vapour pressure defferential of Populus euphratica. J. Desert Res., 1377-1384.

Lu, P., Yunusa, I.A., Walker, R.R., Müller, W.J., 2003. Regulation of canopy conductance and transpiration and their modelling in irrigated grapevines. Funct. Plant Biol. 30, 689-698.

Monteith, J., 1965. Evaporation and environment. Symp. Soc. Exp. Biol., 4.

Naithani, K.J., Ewers, B.E., Pendall, E., 2012. Sap flux-scaled transpiration and stomatal conductance response to soil and atmospheric drought in a semi-arid sagebrush ecosystem. J. Hydrol. 464, 176-185.

Ryszkowski, L., Kedziora, A., 2007. Modification of water flows and nitrogen fluxes by shelterbelts. Ecol. Eng. 29, 388-400.

Shan, L., Deng, X.P., Kang, S.Z., 2002. Current situation and perspective of agricultural water used in semiarid of China. J. Hydrol. Chin., 27-31.

She, D.L., Xia, Y.Q., Shao, M.A., Peng, S.Z., Yu, S.G., 2013. Transpiration and canopy conductance of Caragana korshinskii trees in response to soil moisture in sand land of China. Agrofor. Syst. 87, 667-678.

Shen, Y.L., Yang, S.X., Duan, X.J., 1999. Analysis of the function of protection forest drainage and water consumption. J. Irrig. Drain., 38-40.

Shi, C., Fan, W.B., Zhu k, H., Wang, J.H., 2011. Research on water use pf Populus bolleanau under different irrigation gradients and irrigation systems. China Rural Water and Hydropower, 1-4.

Sommer, R., de Abreu Sáb, T.D., Vielhauera, K., Alessandro Carioca de, A., Folster, H., Vlek, P.L.G., 2002. Transpiration and canopy conductance of secondary vegetation in the eastern Amazon. Agric. Forest Meteorol. 112, 103-121.

Stewart, J., 1988. Modelling surface conductance of pine forest. Agric. Forest Meteorol. 43, 19-35.

Wang, H.L., Guan, H.D., Deng, Z.J., Simmons, C.T., 2014. Optimization of canopy conductance models from concurrent measurements of sap flow and stem water potential on Drooping Sheoak in South Australia. Water Resour. Res. 50, 6154-6167

Whitley, R., Medlyn, B., Zeppel, M., Macinnis-Ng, C., Eamus, D., 2009. Comparing the Penman-Monteith equation and a modified Jarvis-Stewart model with an artificial neural network to estimate stand-scale transpiration and canopy conductance. J. Hydrol. 373, 256-266.

Whitley, R., Taylor, D., Macinnis-Ng, C., Zeppel, M., Yunusa, I., O’Grady, A., Froend, R., Medlyn, B., Eamus, D., 2013. Developing an empirical model of canopy water flux describing the common response of transpiration to solar radiation and VPD across five contrasting woodlands and forests. Hydrol. Processes 27, 1133-1146.

Xinli, D., 2003. Research on Water-Saving Irrigation Technique Development Model and Gravity Sprinkler Irrigation Applieation in Arid Areas Xinjiang. Xi'an University of Technology.

Xinli, D., 2006. Study on development situation of water-saving irrigation in Xinjiang and ecological efficiency of drip irrigation. J. Water Sav. Irrig., 53-56.

Xiubin, H., Zhanbin, L., Mingde, H., Keli, T., Fengli, Z., 2003. Down scale analysis for water scarcity in response to soil-water conservation on Loess Plateau of China. Agric. Ecosyst. Environ. 94, 355-361.

Yunusa, I.A.M., Walker, R.R., Loveys, B.R., Blackmore, D.H., 2000. Determination of transpiration in irrigated grapevines: comparison of the heat-pulse technique with gravimetric and micrometeorological methods. Irrig. Sci. 20, 1-8.

Zeppel, M.J.B., Macinnis-Ng, C.M.O., Yunusa, I.A.M., Whitley, R.J., Earnus, D., 2008. Long term trends of stand transpiration in a remnant forest during wet and dry years. J. Hydrol. 349, 200-213.

Zhao, X.F., Xu, H.L., YeM. Li, J.M., 2009. Summary on the dynamic development of oasis shelter belt system in Xinjiang. J. Arid Land Resour. Environ., 104-109.

Zhou, H., Li, X., Fan, H., Wang, X., Tan, H., Li, A., 2004. Physiological characteristics of several Caragana shrub species under extreme conditions. J. Desert Res. 25, $182-190$.

Zweifel, R., Häsler, R., 2001. Dynamics of water storage in mature subalpine Picea abies: temporal and spatial patterns of change in stem radius. Tree Physiol. 21, 561-569. 